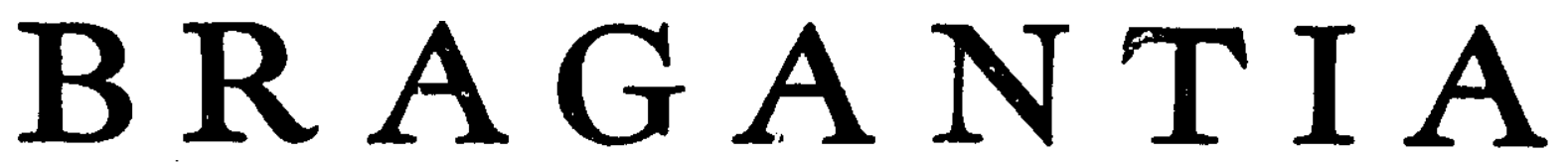

Boletim Técnico do Instituto Agronômico do Estado de São Paulo

Vol. I Campinas, Março de $1941 \quad$ N. 3

\title{
Manchas das fôlhas da mandioca, produzidas por Cercosporas
}

\author{
A. P. Viégas
}

\section{INTRODUÇÃO}

Dentre as espécies de Cercospora assinaladas até o presente em Manihot, duas ocorrem produzindo manchas das fôlhas vivas da mandioca (Manihot ulilissima Pohl). Dessas duas é que tratamos neste trabalho.

As duas espécies - Cercospora henningsii Allesch e Cercospora caribaea Ciferri, bastante comuns aquí no Brasil, são bem distintas. Podem ser fàcilmente separadas, mesmo pelos leigos.

Cercospora henningsii Allesch, mais antiga, pois foi descrita em 1895, ocasiona a Mancha parda da fôlha da mandioca. Cercospora caribaea Ciferri, conhecida mais recentemente, produz a Mancha branca da fôlha da mandioca.

Espécies de Cercospora, tais como C. cassavae Ell. \& Ev., C. manihotis $\mathrm{P}$. Henn., C. cearae Petch, C. panamensis Stev. \& Moore, bem como Septogloeum manihotis Zimmermann, encontradas quando se buscam informes na literatura, não passam de meros sinônimos dessas duas, como haveremos de mostrar mais adiante. C. jatrophae Atks., de acôrdo com Chupp, em carta a nós dirigida, não ocorre nunca em mandioca. 


\section{Mancha parda das fôlhas da mandioca, causada por Cercospora henningsii Allesch}

\section{SUSCETÍ VEIS E SUSCETIBILIDADE DAS VARIEDADES}

Até o presente, a mancha parda das fôlhas da mandioca foi constatada em Manihot ulilissima Pohl $(9,10,13,14,15,18,19,21,23,27$, $30,31,41,42,43,48)\left({ }^{+}\right)$, em $M$. glazionii $(6,17)$ e $M$. piauhyensis $(17)$.

Tôdas as variedades de mandioca (Manihol utilissima Pohl), aparentemente, são suscetíveis aos ataques da moléstia. Constatámos a mancha parda nas seguintes variedades $\left({ }^{++}\right)$: Vassourinha, Bujarra (Alagoas), Mlata-negro (Alagoas), C'ruvela (Alagoas), Alalaia (Alagoas) e em quase tôdas as variedades cultivadas no Estado de São Paulo.

\section{DISTRIBUÍÇÃO GEOGRÁFICA}

$O$ primeiro material de C. henningrii Allesch foi coletado em plantações de mandioca na parte leste do continente africano, em Amboni (2) (tipo). A moléstia ocorre em várias partes do mundo onde a mandicca é cultivada.

Foi constatada até 0 presente: na f́ndia $(6,17,26)$, nas Filipinas (7, 11, 12, 17, 29, 41, 42, 43), em Pôrio-Rico (8, 10, 17, 18, 23, 45, 46), Formosa (13), Uganda (14), nas Antilhas (15), Malaias (16, 47) em Santo Domingo (17, 19, 30), no Cameroun (21), em Madagáscar (24), no Paraguai, no Brasil (5, 9, 25, 27, 28), em Cuba (17), Sião (17), na Indo-China (17), em Zanzibar (37) e Trinidade (44), Flórida $(3,48)$ e China (16).

Em nosso país a mancha parda da fôlha foi assinalada nos Estados de: Pará (5), Pernambuco, Alagoas, Espírito-Santo (31), Rio-de-Janeiro (35), Minas-Gerais (32), São Paulo (27), Paraná, Rio-Grande-do-Sul.

No Estado de São Paulo a moléstia foi observada, até agora, nos seguintes lugares: Valinhos, Taquaral, Louveira, Piracicaba, Campinas, Ribeirão-Preto, Paraibuna, Juquerí, Taubaté, Araras, Ubatuba.

\section{IMPORTÂNCIA ECONÔMICA}

A moléstia, ao que parece, carece de importância econômica. Diminue, é claro, a área verde das fôlhas atacadas, mas, mesmo em casos

(+) Os números entre parêntese referem-se à literatura citada.

$(++)$ Em virtude do número considerável de variedades de H.xn hot utilissima Pohl, os nomes referidos carecem de valor puramente científico. 
severos, a planta não vem a sofrer muito. Nas Filipinas, Reinking (11) se refere aos pequenos danos causados pela moléstia. Miles (46) diz o mesmo, com relação às condições de Pôrto-Rico. Já em 1903, Tracy (48) mostrou os mínimos danos ocasionados pela "spot disease", em Flórida.

\section{Nomes :}

\section{A MOLÉSTIA}

Nas Filipinas a moléstia é designada pelo nome geral de "leafspot" (11) e na Flórida por "spot disease" (48). No Paraguai a mancha parda da fôlha da mandioca é conhecida pelo nome guaraní de mbirú $(+)$. No Brasil, não nos consta que houvesse sido aplicado nome algum especial à enfermidade. Propomos o de - Mancha parda das fôlhas.

\section{História :}

A moléstia tem recebido muito pouca atenção dos agricultores e fitopatologistas do nosso e de outros países. Já não se dá o mesmo com relação ao seu agente etiológico, que tem sido objeto de estudos críticos e até de certa dose de controvérsia. Referimo-nos, evidentemente, aos pontos de vista de Müller e Chupp (28) e Solheim (22).

\section{Sintomatologia :}

Sintomas gerais :- As plantas atacadas pela mancha parda exibem sempre aspecto normal. As fôlhas basais, isto é, mais próximas ao solo ou as mais idosas (48), são sempre as portadoras de maior número de manchas. As hastes, os pecíolos, os pedúnculos florais, flores e frutos não refletem a mesma suscetibilidade orgânica que as fôlhas. Pode-se dizer, portanto, que a moléstia é peculiar aos lobos foliares da mandioca.

Fôlhas :- Ass lesões, quando novas, são diminutas e amareladas. Logo adquirem uma coloração pardo-avermelhada, que, mais tarde, se torna ligeiramente acinzentada. Quando maduras, variam de 5 a 10 milímetros de d:âmətrı (Est. I, fig. 1). Sã planas, p plig snais, ocorrendo na margem ou no centro dos lobos, e atingem ambas as faces. Às vêzes são bem delimitadas pelas nervuras secundárias (Est. III, fig. 3). A margem amarelada que circunda as lesões é estreita, variando de $1 / 3$ a $1 / 2$ de milímetro de largura. (Est. I, fig. 1). Com a idade, a página inferior central das lesões se torna mais escura e aveludada. Isto é devido ao aparecimento dos esporodóquios do fungo causador da mancha (Est. IV, fig. 5).

(+) Comunicação que recebemos do sr. A. de W. Bertoni, chefe do Laboratório de Entomologia e Fitopatologia, em Assunção, Paraguai. 
As lesões são muito maiores que as da mancha branca. $\bigcirc$ tamanho e a côr das lesões são caracteres seguros para identificação dos dois organismos (Cercosporas) causadores destas duas manchas das fôlhas da mandioca.

As lesões ainda se distinguem das produzidas pela Anthracnose e pela Murcha. As lesões da anthracnose da mandioca são irregulares, largas e de côr mais carregada. As da murcha também são amplas, e são portadoras de uma larga zona de transição entre a parte necrosada e a parte sadia do lobo foliar atacado.

Sinais :--.. A moléstia pode ser fàcilmente reconhecida ainda pelos conìdióforos e conídias do patógeno. Quando fôlhas são colhidas e examinadas scb uma lupa, verifica-se que, especialmente na sua face inferior, se erguem pequenos tufos de coloração acinzentada-escura os conìdióforos do fungo (Est. IV, fig. 5). Nas extremidades dêsses conìdióforos, sob condições de umidade e calor, se desenvolvem as conídias (Est. IV, fig. 6).

Sintomas histológicos :- Cortando-se uma lesão da fôlha e examinando-se os cortes sob o grande aumento do microscópio, verificase que o limbo diminue de espessura na porção necrosada, invadida pelas hifas do fungo. As epidermes superior e inferior se deprimem. O tecido em paliçada, embora mantendo sua posição normal, perde seus plastídios, ao mesmo tempo que o seu protoplasma se coagula e se oxida, exibindo coloração pardo-amarelada. $O$ fungo produz substâncias tóxicas, de ação localizada, que se difundem, desorganizando a vida celular em áreas definidas.

tecido lacunoso sofre as mesmas modificações que o em paliçada. A contração dêste é bem mais acentuada.

micélio do fungo é intercelular, septado, hialino quando novo, mas adquire coloração mais carregada com a idade. Não forma haustórios.

Sob os estômatos, o micélio se adensa para dar origem ao estroma (Est. IV, fig. 5). O crescimento do estroma é vigoroso e rápido. Levanta a epiderme. Rasga-a irregularmente.

\section{ETIOLOGIA}

Hennings (2) foi quem primeiro descreveu, em 1895, Cercospora henningsii Allesch, de material colhido em Amboni (localidade tipo), a leste da África (Ost-Afrika). No mesmo ano, Ellis e Everhart (3) descreveram $C$. cassavae em fôlhas de Manihot de material coletado em Flórida. Esta designação foi usada por Young (8), Van Overeem (16), 
Solheim (22), François (36). Stevenson $(10,45)$, depois Toro (23) e, mais recentemente, Seaver e Chardon (36) já haviam observado que C. cassavae Ellis \& Ev. era sinônima de $C$. henningsii Allesch, ou posto dúvidas acêrca da validez de $C$. cassavae Ellis \& Ev.

Em 1902 Zimmermann (4) descreveu Septogloeum manihotis Zimm., em fôlhas de $\boldsymbol{M}$. utilissima nos arredores de Buitenzorg, Java.

De acôrdo com Stevenson (17), Septogloeum manihotis Zimm. seria provàvelmente o mesmo que $C$. henningsii Allesch. Essa opinião nos foi confirmada por Chupp, em carta a nós dirigida.

Hennings (5), trabalhando com o material colhido por D. J. Huber, no Estado do Pará, descreveu Cercospora manihotis P. Henn. em fôlhas de Manihot sp. Diz Hennings "Die Art ist von C. henningsii All. gaenzlich verschieden". Esta nova espécie - Cercospora manihotis P. Henn. - tem sido aceita como boa por alguns investigadores, como, por exemplo, Solheim (22), Grillo (9), Stevenson (17), Baker (42).

De acôrdo com Chupp, Cercospora manihotis P. Henn.(5, 9, 17, 22) é idêntica a Cercospora henningsii Allesch.

Em 1906, Petch (6) descreveu Cercospora cearae Petch em fôlhas de Manihot glaziovii Muel., em Ceilão, Índia. Esta espécie, de acôrdo com Chupp, é idêntica a $C$. henningsii Allesch.

Em 1917 Rangel (32) descreveu Helminthosporium manihotis Rangel, em fôlhas de Manihot aipi, em São João Nepomuceno, Estado de MinasGerais. Examinando material que nos foi remetido pelo sr. Diómedes Pacca, material que êsse nosso colega julga ser idêntico a Helminthosporium maniholis Rangel, pudemos verificar a identidade entre esta última espécie (H. manihotis Rangel) e Cercospora henningsii Allesch.

Recentemente, Ciferri (34) descreveu Helminthosporium hispaniolae Ciferri em fôlhas de Manihot utilissima Pohl, em Valle del Cibao, província de Santiago, Hiato del Yaque, em Santo Domingo. Pudemos examinar e comparar Helminthosporium hispaniolae Ciferri (34) com Cercospora henningsii Allesch. Ambos são idênticos. Esta nossa observação foi confirmada pelo professor Chupp.

Assim sendo, podemos apresentar aquí a seguinte sinonímia de Cercospora henningsii Allesch:

Cercospora henningsii Allesch. Die Pflanzenvelt Öst Afrikas und der Nachbargebiete Teil C:30-35, 48-61. 1895.

Sin. Cercospora cassavae El. \& Ev. Bol. Torr. Bot. Club 22:434440. 1895. 
C. manihotis P. Henn. Hedwigia 41(Beiblatt):15-18. 1902.

C. cearae Petch. Ann. Roy. Bot. Gard. Peradenyia 3:pt.l, pág. 10. 1906.

Septogloeum manihotis Zimmermann. Centralb. f. Bakt. (Abt. 2) 8:216-221. 1902.

Helminthosporium manihotis Rangel. Arquivos Jard. Bot. Rio-deJaneiro. 2:71. Est. 30. fig. 3-4.1917.

\section{Helminthosporium hispaniolae Ciferri. Ann. Mycol. 29:283- 299. 1931.}

\section{Descrição do fungo :}

As conídias, e mesmo os conìdióforos de $C$. henningsii, levados às fôlhas pelo vento ou pelos borrifos de chuva, germinam ràpidamente (Est. IV, fig. 7, a-d,e). Os tubos germinativos são hialinos, septados, cilíndricos e logo se ramificam abundantemente. Anastomoses podem ocorrer entre micélios das conídias em germinação. Por fatores não bem conhecidos ainda, os tubos germinativos ganham os tecidos através das aberturas estomatais das fôlhas. Uma vez no interior do tecido foliar, - micélio se desenvolve mais ou menos ativamente. Invade os espaços intercelulares e, alterando o conteúdo protoplásmico das células ao derredor, produz o primeiro sintoma visível de moléstia, sintoma êsse que se traduz por uma pequena mancha amarelada. Já por esta ocasião, o micélio é largo e de côr pardacenta. À medida que o micélio se desenvolve, sob os estômatos, êle se enovela para dar origem ao primeiro estroma. Outros estromas se formam logo, em posição idêntica. A lesão atinge nesta fase cêrca de 2,5 milímetros de diâmetro. Do estroma, através da abertura estomáłica, irrompem os conìdióforos. São, de princípio, relativamente curtos a ccrn poucos septos. A porção basal dos conìdióforos é pardacenta, e a porção distal, mais clara. Os conìdióforos não demoram a formar, nas suas extremidades, pequenas dilatações que crescem no sentido longitudinal. Estas protuberâncias, hialinas, de parede delgada, variáveis na forma, são os rudimentos das primeiras conídias. À medida que o micélio se alastra em todos os sentidos (ora aparentemente barrados pelas nervuras das fôlhas), a mancha cresce em diâmetro, atingindo na média 5-10 mms. É de côr caraterìsticamente parda, como já descrevemos ao tratar da sintomatologia.

De princípio, os estromas são subepidérmicos. Com o crescimento radial, rompem êste tecido, tornando-se salientes para o exterior. 
Se lesões das fôlhas são postas em câmara úmida, verifica-se que as células do estroma podem alongar-se e transformar-se em conìdióforos típicos. A lesão assim recoberta pelos conìdióforos e conídias tem a côr um tanto acinzentada.

As conídias, depois que atingem a maturidade, destacam-se mecânicamente pelo vento ou pela ação da água da chuva. Ao se destacarem, deixam, no conìdióforo, uma cicatriz circular, bem nítida (Est. IV, fig. 5). Cicatriz idêntica é observada na porção basal das conídias (Est. IV, fig. 6).

Os conìdióforos, à maturidade, são septados, indivisos ou raramente ramificados. Às vêzes se anastomosam lateralmente. Na sua extremidade distal, afilam-se, terminando na cicatriz já referida. Após a perda de sua conídia, um conìdióforo pode originar uma segunda, quer pelo crescimento lateral, logo abaixo da primeira cicatriz، quer pela elongação direta de seu eixo. Há constrição nítida separando o conìdióforo da conídia (Est. IV, fig. 5). Os estromas são relativamente pequenos e medem 20-45 $\mu$ de diâmetro (Est. IV, fig. 5). Os conìdióforos medem, no máximo, $80-100 \mu$ de comprimento e 3-4 $\mu$ de diâmetro.

$O$ estado perfeito associado a Cercospora henningsii Allesch ainda não foi demonstrado existir nos materiais por nós colhidos no Estado de São Paulo. Ghesquière e Henrard (38), no Congo Belga, crêem haver demonstrado a relação existente entre Septogloeum manihotis Zimm. e uma Mycosphaerella manihotis Ghesq. et Henr.

Se Mycosphaerella manihotis Sydow, já assinalada no Brasil $(9,17)$ e África (39), é o estado perfeito de Cercospora henningsii Allesch, também não sabemos.

\section{Germinação de conídias de Cercospora henningsii Allesch:}

À temperatura comum de laboratório, isto é, $23-24^{\circ} \mathrm{C}$, a germinação de conídias de $C$. henningsii foi estudada em bacto-agar, em caixa de petri.

A germinação, quer das conídias, quer dos conìdióforos isolados, quer dos bulbilhos, é perfeita e atinge 100\% em 48 horas.

\section{Conídias :}

Nas condições referidas, as conídias germinam emitindo um tubo hialino, cilíndrico, septado e rarnificado, que varia de 2 a $3,5 \mu$ de diâmetro (Est. IV, fig. 7,a-d). Nem tôdas as células de uma conídia germinam. No geral, as células das extremidades são as primeiras a germinar. A germinação das células centrais, por meio de tubos germinativos laterais, é de mais rara ocorrência. Anastomoses dos tubos germinativos são freqùêntes. 


\section{Conìdióforos :}

Isolados ou em feixes (bulbilhos), germinam emitindo tubos idênticos aos das conídias. A germinação é sempre nas extremidades, em pontos subjacentes às cicatrizes (Est. IV, fig. 7, e).

\section{HISTÓRIA DA VIDA DO PATÓGENO}

\section{Ciclos primários :}

Os ciclos primários na latitude de Campinas se iniciam na época das primeiras chuvas, em setembro-outubro. Aparentemente, os bulbilhos e mesmo conídias produzidos nos estromas das fôlhas caídas são os agentes da infeção primária.

Inoculação : -- Esta se processaria pela ação mecânica dos ventos e dos pingos de chuva. Assim se explica a maior ocorrência das lesões nas fôlhas basais.

Incubação : - As conídias ou mesmo bulbilhos e seus fragmentos, levados às fôlhas, aí germinariam (Est. IV, fig. 7, a-e) e os tubos germinativos ingressariam pelas aberturas estomatais das fôlhas.

Infeção : - O micélio do fungo, agindo por meio de substâncias tóxicas que se difundem pela parede e membrana das células foliares, ocasiona a desorganização localizada dos tecidos.

Saprogênese : - $O$ fungo vive saprofiticamente nas lesões das fôlhas já mortas, caídas no chão.

\section{Ciclos secundários :}

Depois que as lesões primárias atingem 5-10 mms. de diâmetro, em média (Est. I, fig. 1), considerável número de conídias são produzidas, e estas, levadas pelo vento e pela ação mecânica da água das chuvas, iriam iniciar os ciclos secundários, que se repetiriam durante tôda a estação quente e chuvosa do ano, pelo menos para a latitude de Campinas.

\section{CONTRÔLE}

A moléstia, como vimos, carece de importância econômica, sob as condições de clima de São Paulo. Os estragos que produz são mínimos, pelo menos às variedades de mandioca cultivadas aquí em nosso Estado, e por isso não são necessárias quaisquer medidas de contrôle por parte de nossos agricultores.

Marcus (47) sugere a aplicação de calda bordalesa para prevenir os poucos danos causados pela moléstia. Não se refere, porém, à concentração da calda a ser empregada. 
Em nossas experiências preliminares, em estufas e em campo, verificamos que mesmo os brotos novos suportam calda à concentração de 1\%. Essa concentração talvez possa ser abaixada inda mais, barateando o custo da aplicação do protetante. A calda com dificuldade se espalha à superfície das fôlhas. A adição de açúcar melhora, mas não resolve definitivamente o problema da adesão da calda.

\section{LITERATURA CITADA}

1. Saccardo, P. A. Em Sylloge fungorum 14:1104. 1890.

2. Hennings, P. Pilze Ostafrikas. Em A. Engler Die Pflanzenvelt Ost Afrikas und der Nachbargebiete Teil C:30-35,48-61.1895.

3. Ellis, J. B. e B. M. Everhart. New species of Fungi II. Florida Fungi. Bol. Torrey Bot. Club 22:434-440. 1895.

4. Zimmermann, A. Über einige an tropischen Kulturpflanzen beobachtete Pilze II. Centralb. f. Bakt. (Abt.2) 8:216-221. 1902.

5. Hennings, P. Fungi paraenses II. I. D. J. Huber collecti. Beiblatt zur Hedwigia 41:(15)-(18). 1902.

6. Petch, J. Descriptions of New Ceylon Fungi. Ann. Roy. Bot. Gard. Peradeniya 3: pt.1, 1-10. 1906.

7. Baker, C. F. A review of some Philippine plant diseases. Phil. Agr. \& Forest. 3:157-164. 1914.

8. Young, Esther. Studies in Porto Rican Parasitiz Fungi II. Mycologia 8:42-46. 1916.

9. Grillo, H. V. da Silveira. Lista preliminar dos fungos assinalados em plantas do Brasil. Rodriguesia 2: n. ${ }^{\circ}$ especial: 39-96. 1936.

10. Stevenson, J. A. Diseases of Vegetable and Garden Crops. Jour.

Dept. Agr. Porto Rico 1:93.117. 1917.

11. Reinking, Otto. Philippine economic-plant diseases. Philippine Jour. Sci. 13: Sec. A. 165-274. pl.1-22. fig. 1-43. 1918.

12. Reinking, Otto. Philippine Plant diseases. Phytopath. 9:128.1919. 13. Sawada, Kaneyoshi. Descriptive catalogue of the Formosan fungi. Formosa Agr. Exp. St. Special Bul. 19:219. 1919.

14. Snowden, J. D. Report on the Government Botanist for the period lst April to 31st Dec. 1920. Ann. Report Dept. Agr. Uganda for the nine months ending December 31st, 1920. págs. 43-46. 1921.

15. Nowell, William. Em Diseases of crop plants in the Lesser Antilles. Pág. 335. The West India Commitee. London. 1923. 
16. Van Overeem, C. Cercosporaceae. Cercospora cassavae Ell. \& Ev. Icones fungorum Malayensium 10:14. pl. 1. 1925.

17. Stevenson, John A. Foreign plant diseases. U. St. Dept. Agr. Publication. págs. 1-198. 1926.

18. Seaver, J. F. and C. E. Chardon. Scientific survey of Porto Rico and the Virgin Island. New York Academy of Sciences 8:1-208. 1926.

19. Toro, R. A. Fungi of Santo Domingo. Mycologia 19:66-85. pl.5-6. 1927.

20. Seymour, A. B. Em Host index of the fungi of North America. Pág. 459. Cambridge, Harvard Univ. Press. 1929.

21. Dufrénoy, J. e L. Hedin. La mosaîque des feuilles du manioc au Cameroun. Revue de Bot. Appliq. et d'Agric. Tropicale 9:361-365. pl. 1. 1929.

22. Solheim, W. G. and F. L. Stevens. Cercospora studies. II. Some tropical Cercosporae. Mycologia 23:365-405. fig.1-12. 1931.

23. Toro, Raphael A. The Cercospora of Puerto Rico. The Journ. Dept. Agr. Porto Rico 15:1-17. 1931.

24. Bouriquet, G. Les maladies du manioc à Madagascar. Rev. Path. Veg. et Ent. Agr. 19:290-297. pl. 1. 1932.

25. Müller, A. S. Brazil : preliminary list of diseases of plants in the State of Minas Gerais. Intern. Bul. of Plant Protection 8:193-198. 1934.

26. Su, U. I. India : new diseases of crops during the year 1934-35 in Burma. Inst. Bul. Plant Prot. 9:273. 1935.

27. Bitancourt, A. A. e outros. Relação das doenças e fungos parasitas observados na Seç̧ão de Fitopatologia durante os anos 1933 e 1934. Arquivos do Inst. Biol. 6:205-211. 1935.

28. Müller, A. S. e Charles Chupp. Cercosporae de Minas Gerais. Arq. Inst. Biol. Veg. 1:213-220. 1935.

29. Teodoro, Nicanor. An enumeration of Philippine fungi. Commonwealth of the Philippine Dept. of Agr. and Commerce (Manila) Tech. Bul. 4:1-585. 1937.

30. Gomez, Menor O. Notas fitopatologicas. Rev. Agr. St. Domingo 28:170-172. fig. 1-3. 1937.

31. da Silva, Sebastião Gonçalves. Aspecto fitossanitário das principais plantas cultivadas no estado do Espírito-Santo. Revista da Soc. Brasileira de Agronomia 2:80-84. 1939. 
32. Rangel, Eugênio. Alguns fungos novos do Brasil. Arquivos do Jardim Bot. do Rio-de-Janeiro 2:71. Est.30. fig.3-4. 1917.

33. Saccardo, P. A. Sylloge fungorum 25:820. 1935.

34. Ciferri, G. Mycoflora dominguensis exciccata. Ann. Mycol 29:283. 299. 1931.

35. Pacca, D. W. Contribuíção ao estudo das doenças da mandioca. Rodriguesia 3:171-178. fig.1-9. 1937.

36. François, Edmond. Le manioc, sa production et son utilisation. Revue de Bot. Applig. et d'Agriculture Tropicale 18:533-573, 682-707. 1938.

37. Welsford, Miss E. J. Report of the Government Mycologist for the year 1924. Ann. Report Dept. Agr. Zanzibar 1924:15. 1925.

38. Ghesquière, J. e J. Henrard. Sphaeriacée nouvelle des feuilles du manioc au Congo Belge. Rev. Zool. Afr. 12:Suppl. Bot. 4:1-2. figs.a-d. 1924.

39. Wallace, G. B. Report of the Mycologist. Ann. Report Dept. Agr. Tanganyika Territory 1932:76-80. 1933. (R.A.M. 12:552).

40. Wollenweber, H. W. III. Hyphomycetes. Em Sorauer Handbuch der Pflanzenkrankheiten 32:690. 1932.

41. Reinking, Otto A. Host index of diseases of economic plants in the Philippines. The Philip. Agriculturist 7:38-54. 1919.

42. Baker, F. C. Second supplement to the list of the lower fungi of the Philippine Islands. A bibliographic list chronologically arranged, and with localities and hosts. The Philip. Journ. Sci. 46:479-536. 1931.

43. Roldan, E. F. New or noteworthy lower fungi of the Philippine Islands. II. The Philip. Journ. Sci. 66:7-13. pl. 1-4. 1938.

44. Thorold, C. A. - A further preliminary list of Trinidad fungi. Págs. 1-30 + I-VIII. Government Printing Office. Port-of-Spain. 1931.

45. Stevenson, John A. Report of the pathologist. Porto Rico Insular Agric. Exp. St. Ann. Report 1916-17:37-98. 1918.

46. Miles, L. E. Some diseases of economic plants in Porto Rico 7:345351. 1917.

47. Marcus, A. Maniok, Manihot utilissima Pohl. Der Tropenpflanzer 38:144-157. 1935.

48. Tracy, S. M. Cassava. U. St. Dept. Agr. Farmer's Bul. 167:1-32. fig.1-11. 1903. 


\section{Mancha branca das fôlhas da mandioca, causada por Cercospora caribaea Ciferri}

\section{SUSCETÍfEIS E SUSCETIBILIDADE DAS VARIEDADES}

Até o momento, a mancha branca das fôlhas da mandioca foi constatada atacando apenas Manihot, especialmente Manihot utilissima Pohl.

Quase tôdas as variedades de mandioca cultivadas são suscetíveis à moléstia.

As variedades - Assú, Mata-fome, Olandỵ-branca, Vassourinha são muito suscetíveis.

Em Ubatuba, observámos que a variedade Macaé apresenta alta resistência a esta moléstia.

\section{DISTRIBUÍÇÃO GEOGRÁFICA}

A mancha branca ocorre com mais intensidade ao longo da costa atlântica brasileira que no hinterland. Em Ubatuba, aquí em nosso Estado, a moléstia poderia ser considerada como tendo alguma importância econômica, dado o caráter acentuado com que ataca alí certas variedades. Já nos planaltos e nos climas mais secos, a mancha branca cede lugar à mancha parda.

A mancha branca já foi assinalada nos seguintes países: Cuba (6) (ilustr. pl. 7, fig. 3), Guiana Inglesa (7) (tipo), Pôrto-Rico (7), Panamá (7), Árica (3), Sierra Leone (8), Trinidade (9).

No Brasil ela está assim distribuída : Estado de S. Paulo (constatamola em Ubatuba, Roseira e, mais recentemente, em Campinas), MinasGerais $(1,2)$, Espírito-Santo (5), Alagoas (em material proveniente dos munícipios de União e S. Miguel dos Campos), Pernambuco (em material proveniente do município de Vitória), Rio-Grande-do-Sul (município de Canoas).

\section{IMPORTÂNCIA ECONÔMICA}

Em certas regiões do nosso Estado, como, por exemplo, Ubatuba, a mancha branca atinge foros de importância, durante os meses mais 
quentes do ano. As lesões são numerosas e aparecem mesmo nas fôlhas relativamente novas da planta.

\section{Nomes :}

\section{A MOLÉSTIA}

Não sabemos, até o presente, se a moléstia recebeu um nome particular. Empregamos aquí o de Mancha branca da fôlha da mandioca. Essa designação nos parece apropriada, prática, pois, dessa maneira, a moléstia pode ser fàcilmente separada da primeira descrita. Comparem-se as estampas coloridas I e II.

\section{História :}

Ao que nos consta, a moléstia foi constatada, pela primeira vez, na Guiana Inglesa, no continente sul-americano (7). Já em 1911, Cardin (6) a havia constatado em Cuba. A ilustração dada por Cardin (6), em sua estampa 7 , figura 3 , indica claramente que êle se referia a esta moléstia. Diz Cardin (6):

"En las hojas de la yuca se presentan en la epoca de la seca, unas manchitas blancuzas, y irregulares de bordo obscuro, las cuales son producidas por um hongo parasitico summamente pequeño que forma essas manchas en las hojas $y$ que en alguns casos son algo numerosas."

Foi, pois, Cardin (6) o primeiro a se referir, de modo claro, à moléstia de que tratamos aquí.

Depois de Cardin (6), outros autores (1-8) se preocuparam, não com o estudo da moléstia, mas sim com o do seu agente causal-Cercospora caribaea Ciferri. Devido às divergências de opiniões acêrca da posição sistemática do patógeno $(2,7)$, o fungo atraiu mais a atenção dos micologistas que dos patologistas.

\section{Sintomatologia :}

Sintomas gerais : - A mancha branca da fôlha é mais comum, ou melhor, atinge maior desenvolvimento nas plantações das baixadas, ao longo do litoral brasileiro, onde a temperatura e umidade são mais elevadas. As fôlhas basais são as mais afetadas.

Sintomas morfológicos : - Os primeiros sintomas da mancha branca da fôlha da mandioca são umas descolorações amareladas do 
limbo. Logo depois o centro se torna pardacento, para, em seguida, se cercar de uma orla vermelho-arroxeada. A mancha tem, então, um milímetro de diâmetro. A seguir, a parte central se torna branca (Est. II, fig. 1). A mancha interessa ambas as páginas do limbo. $\mathrm{Na}$ página dorsal (inferior) a orla vermelha é mais nítida.

As manchas são numerosas. São mais ou menos circulares e atingem, no máximo, 5 milímetros de diâmetro.

Sintomas histológicos : - Examinando-se uma lesão sob o microscópio, especialmente na face dorsal do folíolo, observam-se numerosíssimos esporodóquios do fungo, formados de conìdióforos pardoamarelados, geniculados, septados, tortuosos e bastante longos (Est. IV, fig. 8). Tais conìdióforos são portadores de conídias hialinas, septadas, providas, no geral, de duas cicatrizes grandes (Est. IV, fig. 9), em ambas as extremidades. As conídias nascem em cadeias e medem $4-8 \times 15-45 \mu$ na média (7).

A porção central branca da lesão é delgada, cêrca de metade da espessura normal da fôlha. O tecido em paliçada, bem como o tecido lacunoso logo perdem a clorofila e entram em colapso, sofrendo, de início, como que oxidação. As células se tornam vermelhas, parecendo difundir uma substância corante que impregna as células ao derredor. Depois desta reação as células perdem a côr. Tornam-se alvas, transparentes (bleaching). Neste estado as hifas hialinas e mais ou menos escuras do fungo podem ser estudadas com facilidade. O micélio interno (7) é septado, ramificado, e de 2 a 5 u de diâmetro (7).

\section{ETIOLOGIA}

A moléstia é causada pelo fungo até agora conhecido tão sòmente pelo seu estado imperfeito - Cercaspora caribaea Cif. (2).

Esta Cercospora foi por muito tempo confundida com $\mathcal{C}$. henningríi Allesch (7).

Solheim e Stevens (7), verificando que os esporos eram dispostos em cadeias, propuseram o novo gênero-- Ragnhildiana - para conter a espécie. Grillo (4) e Roger (3) aceitaram o nome proposto por Solheim e Stevens. Todavia, Chupp e Müller (2) não concordaram com êsse ponto-de-vista, argumentando que o caráter - esporos catenulados 
é muito fraco para com êle se erigir um gênero. Neste nosso trabalho preferimos seguir Müller e Chupp (2).

\section{Descrição do fungo :}

Sôbre isto, consultar os trabalhos de Solheim e Stevens (7), Müller e Chupp (2).

A sinonímia de Cercospora caribaea Cif. é a seguinte:

Ragnhildiana manihotis Stevens e Solheim. Mycologia 23:365-405. 1931.

Cercospora panamensis Stev. e Moore. In lit.

\section{LITERATURA CITADA}

1. Müller, A. S. Brazil : preliminary list of diseases of plants in the State of Minas Gerais. Internat. Bul. of Plant Protection 8:193-198. 1934.

2. Müller, A. S. e C. Chupp. Cercosporae de Minas Gerais. Arquivos Inst. Biol. Veg. 1:213-220. 1935.

3. Roger, L. Quelques champignons exotiques nouveaux ou peu connus. Bul. Soc. Mycol. France 50:317-332. fig. 1-9. 1934.

4. Grillo, H. V. da Silveira. Lista preliminar dos fungos assinalados em plantas do Brasil. Rodriguesia 2:n.` especial:39-96.1936.

5. da Silva, Səbastião Gonçalves. Aspecto fitossanitário das principais plantas cultivadas no Estado do Espírito-Santo. Revista da Soc. Brasileira de Agronomia 2:80-84. 1939.

6. Cardin, Patrício. Insectos y enfermedades de la yuca en Cuba. Bol. Est. Exp. Agr. Cuba 20:1-28. pl. 1-8. 1911.

7. Solheim, W. G. and F. L. Stevens. Cercospora studies. II. Some tropical Cercosporae. Mycologia 23:365-405. fig. 1-12. 1931.

8. Deighton, F. C. Mycological work. Report Depart. Agr. S. Leone 1934:18-22. 1936.

9. Baker, R. E. D. Additions and corrections to the further preliminary list of Trinidad fungi by C. A. Thorold, 1931. Tropical Agriculture 14:316-319.1937.

\section{AGRADECIMENTOS}

Queremos deixar aquí externados os nossos agradecimentos ao professor Charles Chupp, da Universidade de Cornell, pela boa acolhida com que nos atendeu, ajudando-nos enormemente em nossos trabalhos, 
no que concerne à sinonímia, literatura e outras informações das várias espécies conhecidas das Cercosporas em plantas afins à mandioca ; ao professor $\mathrm{H}$. $\mathrm{H}$. Whetzel, da mesma Universidade, por cópias de diagnoses e referências acêrca da literatura. Desejamos também agradecer ao dr. R. Ciferri, da Facoltá Agraria e Forestale della R. Università, Firenze, Itália, pela remessa de material tipo de Helminthosporium hispaniolae Ciferri ; ao sr. Diómedes W. Pacca, do Jardim Botânico do Riode-Janeiro, por material de Helminthosporium manihotis Rangel; ao sr. O. A. Drummond, da Escola Agrícola de Viçosa, Minas-Gerais, por espécimes enviados; ao sr. José Clovis de Andrade, da Inspetoria do Ministério de Agricultura em Pernambucc; ao sr. Milton Coelho, da Secção de Fomento, Maceió, Alagoas, pela remessa de material para estudos; ao dr. G. R. Bisby, do Imperial Mycological Institute, Kew, Surrey, Inglaterra, por preciosas informações e referências.

A outros que, direta ou indiretamente, contribuíram para a execução dêste trabalho, o autor se confessa imensamente agradecido.

Os desenhos foram todos feitos primeiramente a lapis, pelo autor, e, ao depois, passados a nanquim pelo sr. José de Castro Mendes, desenhista. As estampas coloridas são de autoria do sr. Mendes.

\section{EXPLICAÇ̃̃O DAS ESTAMPAS}

Estampa I - Fig. 1. Fôlha de mandioca exibindo lesões produzidas pela Mancha parda, causada por $C$. henningsii Allesch.

Estampa II - Fig. 2. Fôlha de mandioca exibindo lesões produzidas pela Mancha branca, causada por $C$. caribaea Cif.

Estampa III - Fig. 3. Fotografia de lesões produzidas pela C. henningsii Allesch. Aumento: 2 vêzes, aproximadamente. Fig. 4. Fotografia de lesões produzidas por $C$. caribaea Cif. Aumento: 4 vêzes, aproximadamente.

Estampa IV - Fig. 5. Esporodóquio de C. henningsii Allesch, muito aumentado, e visto em corte, para mostrar o estroma basal (e), os conìdióforos (c) e as conídias (ca).

Fig. 6. Conídias de $C$. henningsii Allesch.

Fig. 7. Várias conídias de $C$. henningsii Allesch, em germinação (a-d); germinação de conidióforos (e).

Fig. 8. Esporodóquio de Cercospora caribaea Cif.

Fig. 9. Conídias de C. caribaea Cif. 
ESTAMPA I

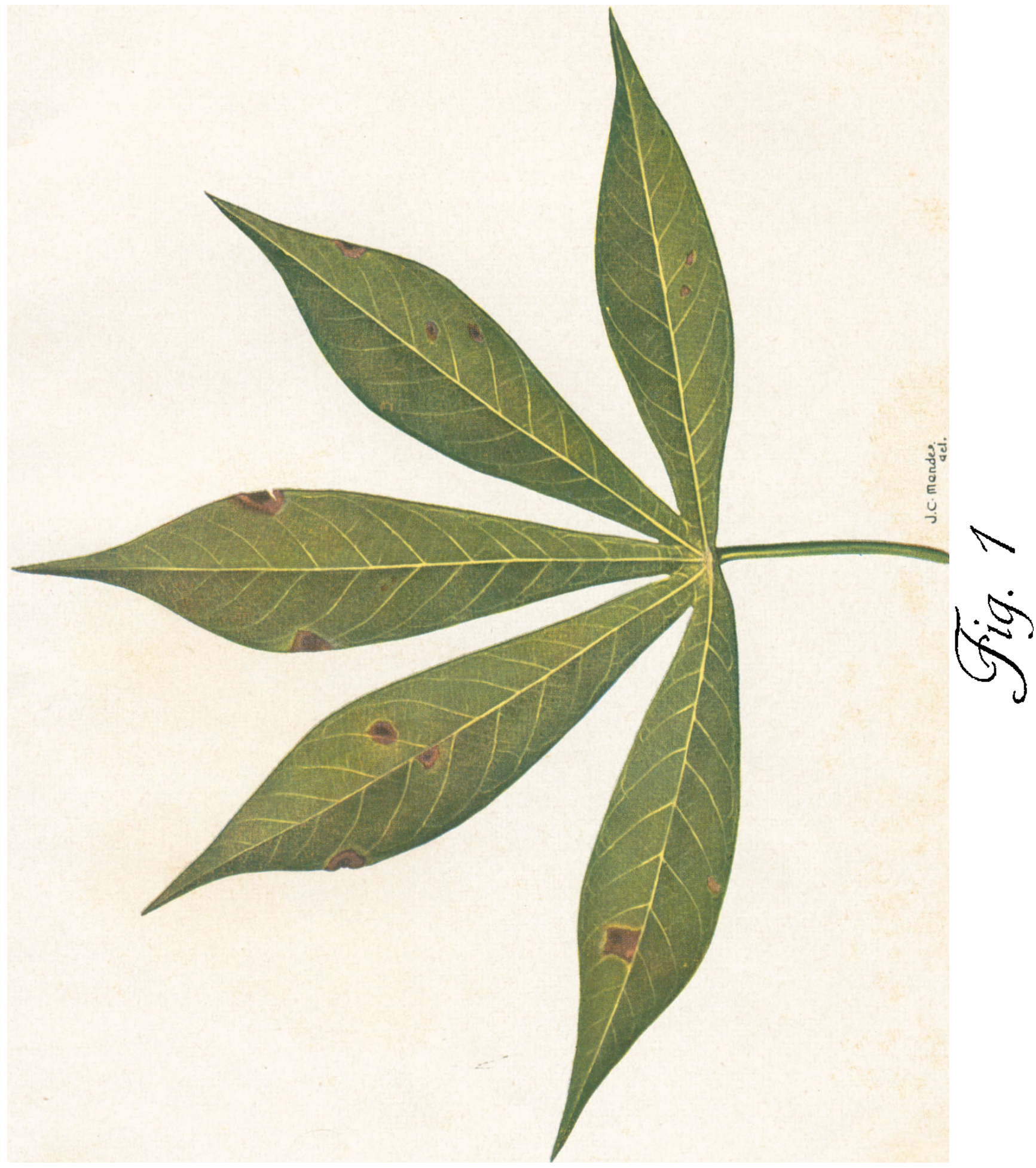


ESTAMPA II

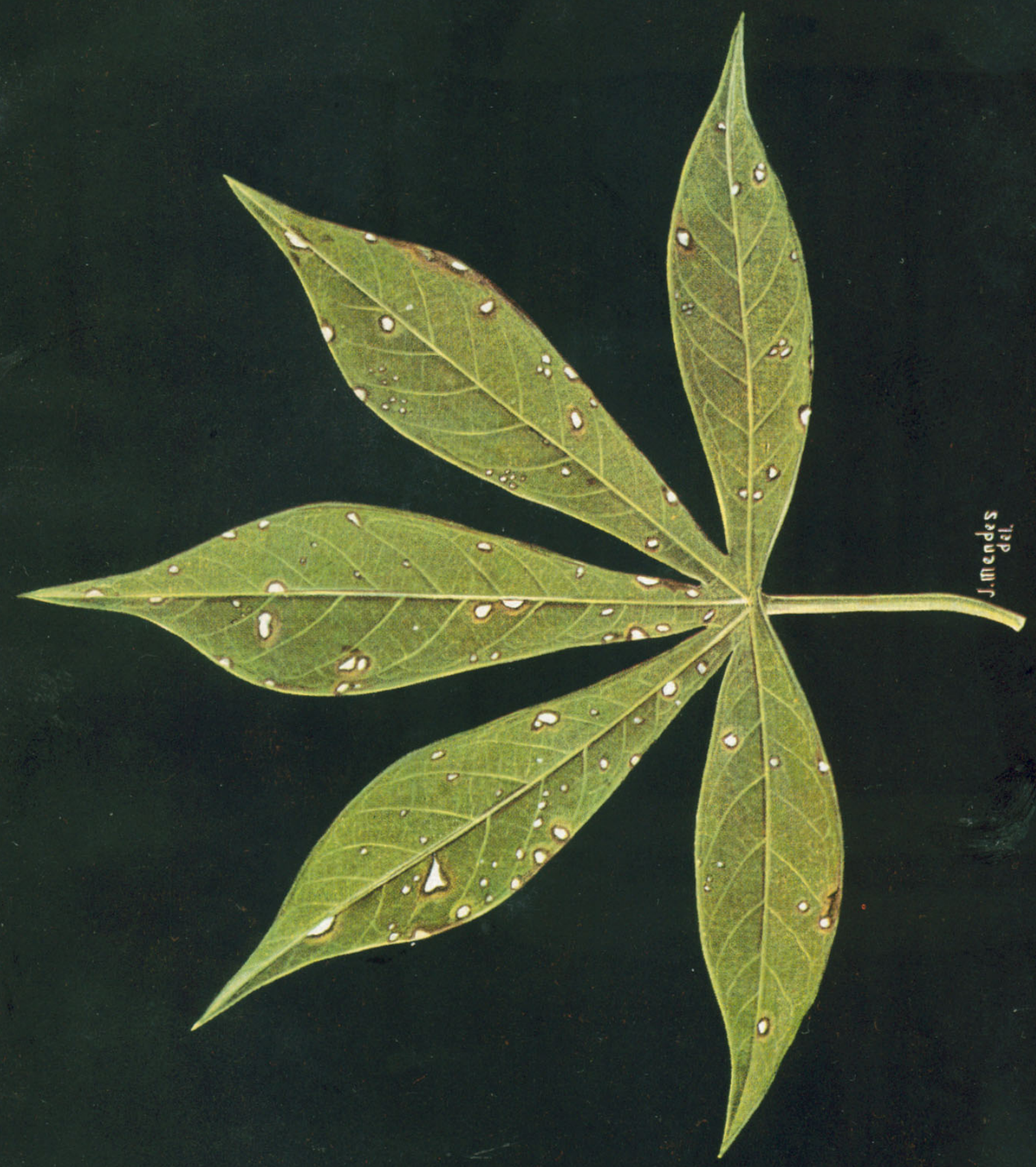

OV

$(j)$ 


\section{ESTAMPA \|I}
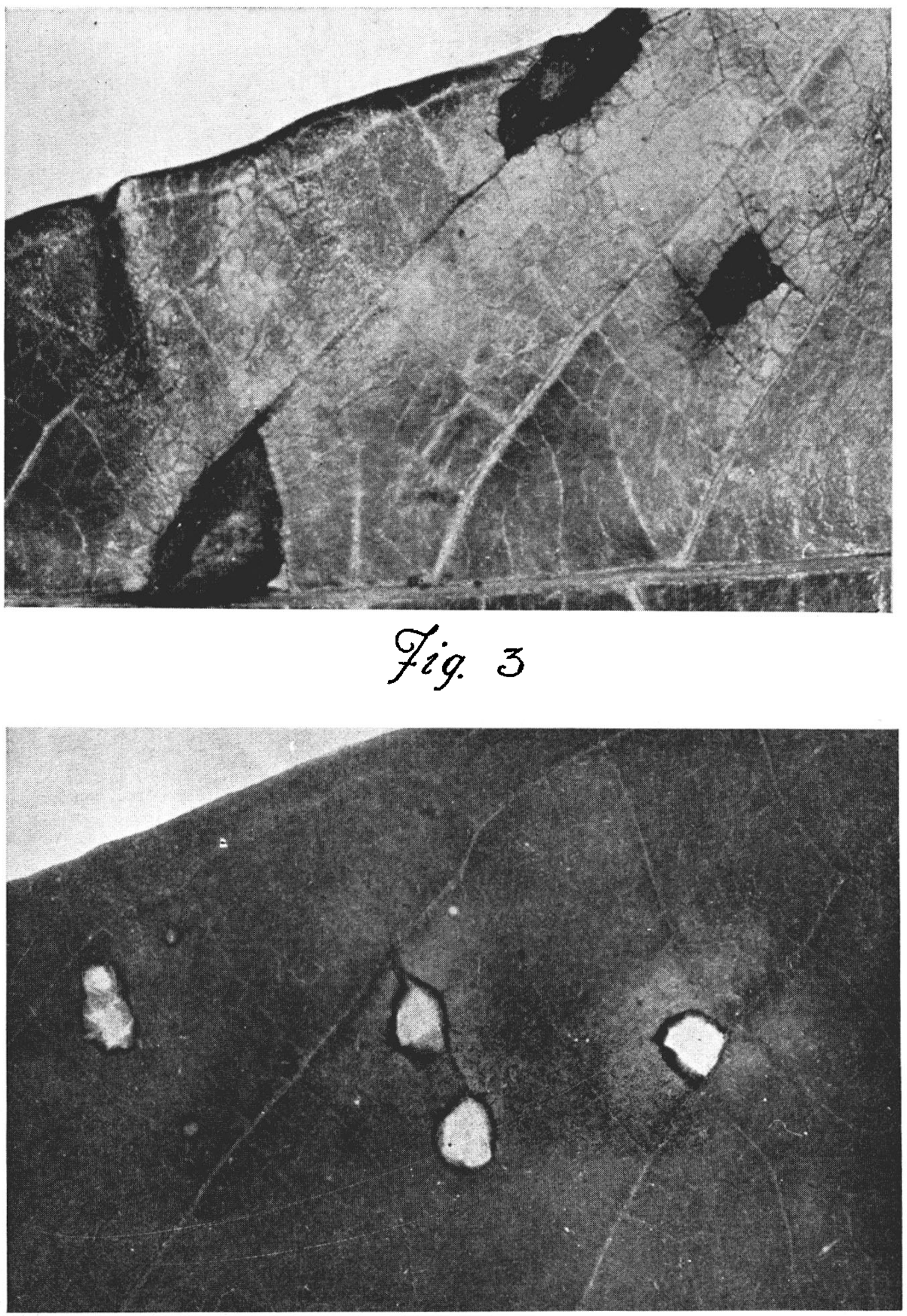

Fig. 4 
ESTAMPA IV

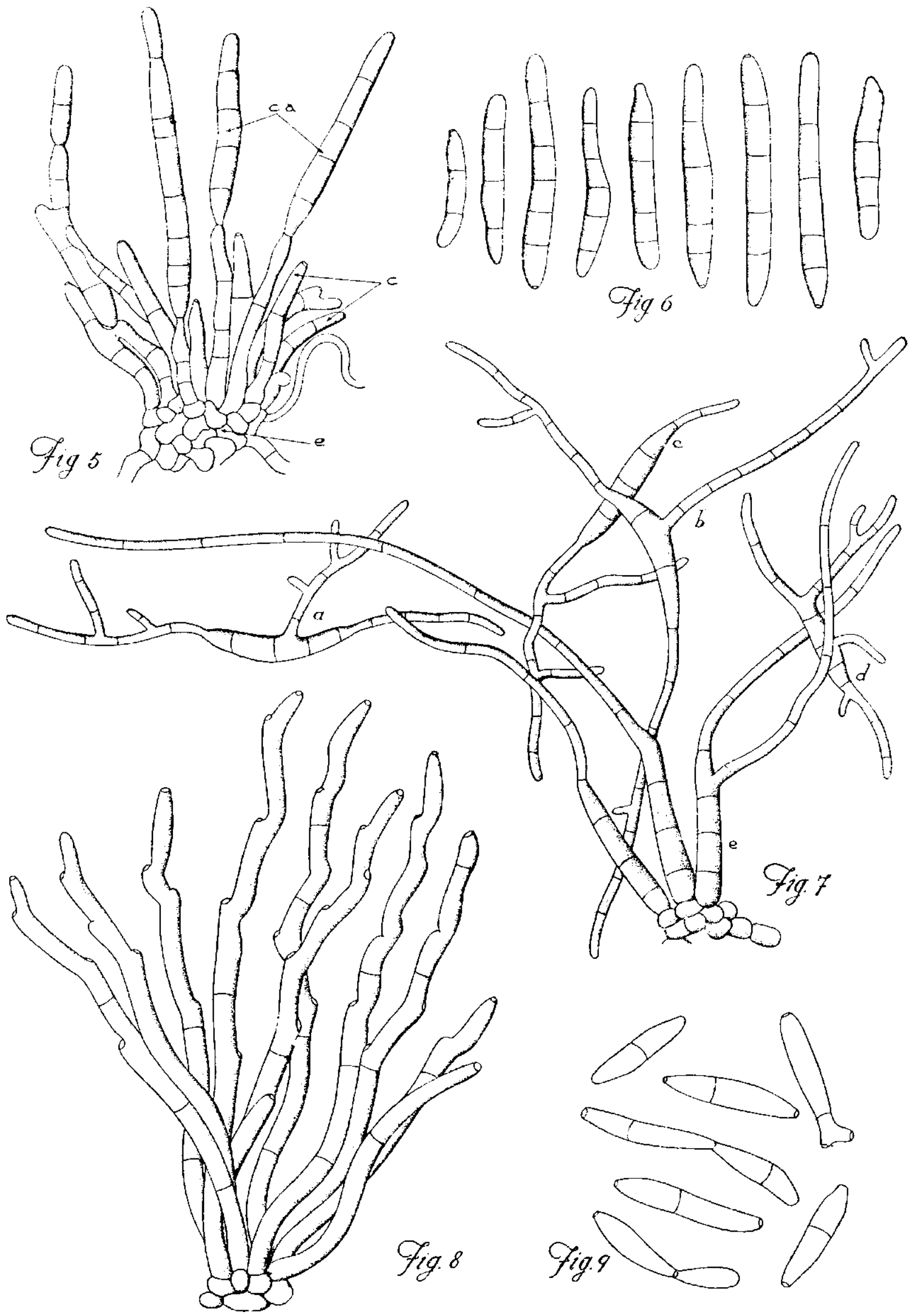

